\title{
Penetapan Kadar Tanin Ekstrak Daun Pagoda (Clerodendrum Paniculantum) Dengan Metode Spektrofotometri Visible Dan Titrasi Permanganometri
}

\author{
Elly Mulyani ${ }^{\mathrm{a}, 1^{*}}$, Herlina ${ }^{\mathrm{a}, 2}$, Kurnia Suci ${ }^{\mathrm{a}, 3}$ \\ aD3 Farmasi, Sekolah Tinggi Ilmu Kesehatan (STIKES) Al Fatah. J1. Indra Giri gang 3 serangkai, Padang Harapan, Bengkulu, Indonesia. \\ ${ }^{1}$ mulyanielly17@gmail.com* \\ *korespondensi penulis
}

INFO ARTIKEL

Diterima :

3I-I2-202I

Direvisi :

04-0I-2022

Disetujui :

04-0I-2022

\section{Kata kunci:}

Clerodendrum

paniculantum;

Tanin;

Spektrofotometri Visibel;

Permanganometri.

\section{ABSTRAK}

Indonesia merupakan negara yang memiliki beraneka ragam tanaman obat yang salah satunya adalah tanaman pagoda (Clerodenrum paniculantum). Daun Pagoda (Clerodenrum paniculantum) mengandung senyawa flavanoid, terpenoid, tanin, alkaloid, sterol dan glikosida. Uji identifikasi tanin dari ekstrak daun pagoda penelitian (Hafiz dkk, 2016) dan (Fitriana, 2018) menjelaskan bahwa daun pagoda positif mengandung senyawa tanin yang belum diketahui kadarnya. Oleh karena itu, peneliti melakukan penetapan kadar tanin pada daun pagoda(Clerodenrum paniculantum). Daun pagoda yang telah dikeringkan di estraksi secara maserasi dengan mengunakan pelarut etanol $96 \%$ kemudian dilakukan uji kualitatif dan kuantitatif. Uji kualitatif menggunakan preaksi warna $\mathrm{FeCl3} \mathrm{I} \%$ dan uji kuantitatif mengunakan dua metode yaitu Spektrofotometri Visibel dan titrasi permanganometri. Hasil dari kualitatif dengan menambahkan $\mathrm{FeCl} 3$ terjadi perubahan warna biru kehitaman menunjukan bahwa ekstrak daun pagoda pmengandung tanin. Hasil dari uji kuantitatif menggunakan spektrofotometri Visibel didapat kadar tanin yaitu 4,I46\% (I5 ppm), 5,546\% (20 ppm) dan 7,598\% (30 ppm). Sedangakan menggunakan metode permanganometri didapatkan kadar rata-rata yaitu $0,443 \%$

Key word:

Clerodendrum

paniculantum; Tannins;

Visible spectrophotometry;

Permanganometric.

\section{ABSTRACT}

Indonesia is a country that has a variety of medicinal plants, one of which is the pagoda plant (Clerodenrum paniculantum). Pagoda leaves (Clerodenrum paniculantum) contain flavonoid compounds, terpenoids, tannins, alkaloids, sterols and glycosides. The tannin identification test from the research pagoda leaf extract (Hafiz et al, 2016) and (Fitriana, 2018) explained that the positive pagoda leaf contained an unknown level of tannin compounds. Therefore, the researchers determined the levels of tannins in pagoda (Clerodenrum paniculantum) leaves. The dried pagoda leaves were extracted by maceration using $96 \%$ ethanol solvent and then qualitative and quantitative tests were carried out. The qualitative test used $\mathrm{I} \% \mathrm{FeCl} 3$ color reaction and the quantitative test used two methods, namely visible spectrophotometry and permanganometric titration. The results of the qualitative by adding $\mathrm{FeCl} 3$ there was a blue-black color change indicating that the pagoda leaf extract contains tannins. The results of the quantitative test using visible spectrophotometry obtained tannin levels of 4.I46\% (I5 ppm), 5.546\% (20 ppm) and 7.598\% (30 ppm). While using the permanganometry method, the average level was $0.443 \%$

This is an open access article under the $\mathrm{CC}-\mathrm{BY}-\mathrm{SA}$ license. 


\section{Pendahuluan}

Kekayaan alam indonesia sangat beraneka ragam, hampir segala jenis tumbuhan dapat tumbuh di Negara ini. Sebagian besar tanaman di Indonesia sudah banyak yang di gunakan sebagai pengobatan penyakit, dari zaman nenek moyang hingga saat ini (Sjahid, 2008).

Para ahli ilmu pengobatan yang dikenal dengan istilah tabib membuat ramuan obat yang bahan bakunya berasal dari hutan. Diperkirakan hutan Indonesia menyimpan potensi tumbuhan obat sebanyak 30.000 jenis, di antaranya 940 jenis telah dinyatakan berkhasiat obat, dimana sekitar $78 \%$ masih diperoleh melalui pengambilan langsung dari hutan (Nurrani, 20I5)

Metabolit sekunder adalah senyawa hasil biogenesis dari metabolit primer. Kandungan senyawa metabolit sekunder telah terbukti bekerja sebagai derivate antikanker, antibakteri dan antioksidan, antara lain adalah golongan alkaloid, tanin, golongan polifenol dan turunannya (Hayati $\mathrm{dkk}, 2010)$.

Pada tahun 1796, Seguin mengaplikasikan istilah tanin. Tanin merupakan senyawa zat organik yang sangat kompleks dan terdiri dari senyawa fenolik yang banyak terdapat pada bermacammacam tumbuhan. Tanin tersebar hampir pada seluruh bagian tumbuhan seperti pada bagian batang, kulit kayu, buah dan daun (Sajaratud, 2013).

Tanin berbentuk serpihan mengkilat berwarna kekuningan sampai coklat muda atau serbuk amorf, tidak berbau, atau sedikit berbau khas (Depkes RI, I995)

Tanaman pagoda (Clorodenrum paniculantum) biasanya bisa kita temui di perkarangan rumah, karena sering dijadikan tanaman hias oleh sebagian masyarakat di Indonesia (Shivastava dan patel, 2007). Senyawa kimia yang terkandung di dalam tanaman pagoda yaitu flavanoid, terpen, tanin, alkaloid, sterol dan glikosida (Hafiz dkk, 2016)

Pada penelitian dengan mengunakan metode spektrofotometri ini digunakan estrak daun pagoda sebagai sampel. Metode ini merupakan metode yang menggunakan sumber radiasi sinar tampak (380-780 $\mathrm{nm}$ ) dengan instrument spektrofotometer pada teknik analisisnya (Mulja dan suharman,1995; Amelia,2015)

Permanganometri merupakan metode yang sederhana, mudah, dan mempunyai tingkat ketelitian yang cukup tinggi. Sehingga, metode ini sering digunakan sebagai metode analisis (Mulja dan suharman, 1995; Amelia, 2015).

Penelitian dengan dua metode ini dilakukan untuk mengetahui metode yang efektif untuk penetapan kadar estrak dari daun pagoda (Mulja dan suharman, 1995; Amelia, 2015).

Uji identifikasi tanin dari ekstrak daun pagoda yang dilakukan oleh (Hafiz dkk, 2016) dan (Fitriana, 2018) dijelasakn bahwa daun pagoda positif mengandung senyawa tanin yang belum diketahui kadarnya. Oleh sebab itu, upaya lanjut sangat di perlukan untuk mengetahui kadar tanin pada daun pagoda. Pada penelitian kali ini, penetapan kadar tanin dari estrak daun pagoda akan menggunakan dua metode yaitu metode spektrofotometri uv-vis dan metode titrasi pemanganometri.

\section{Metode}

Penelitian telah dilakukan di Laboratorium STIKES Al-Fatah Bengkulu. Daun pagoda yang digunakan sebagai sempel pada penelitian ini telah di verifikasi di Laboratorium Biologi Universitas Bengkulu dengan surat pemeriksaan No. 99/ UN30.I2.LEB.BIOLOGI/PM/20I9.

\section{Alat dan Bahan}

Spektrofotometer UV-Vis mikropipet volume I00- $1000 \mu 1$ dan 0,5-5ml, magnetic stirrer, buret, pipet volume, alat-alat gelas laboratorium, dan alat pelindung diri 'Asam Galat, Folin Ciocalteu, $\mathrm{Na} 2 \mathrm{CO} 3$ 15\%, Etanol 96\%, Asam Oksalat, $\mathrm{H} 2 \mathrm{SO} 4$ $4 \mathrm{~N}, \mathrm{KMnO} 4 \mathrm{0}, \mathrm{IN}$, Indigo Carmine, Aquadest.

\section{Jalannya Penelitian.}

Pembuatan ekstrak daun pagoda secara maserasi

Sebanyak 650 gram serbuk daun pagoda (Clerodendrum paniculanum) dimasukkan ke dalam wadah maserasi. Tambahkan pelarut etanol 96\% dengan volume etanol 2 liter dan serbuk simplisia terendam dan dibiarkan selama 3-4 hari. Maserat yang diperoleh kemudian di pekatkan menggunakan rotary evaporator untuk mendapatkan ekstrak kental (Amelia, 2015)

\section{Penetapan kadar tanin secara spektrofotometri \\ I. Larutan baku induk}

Timbang asam galat sebanyak $10 \mathrm{mg}$, larutkan terlebih dahulu menggunakan aquadest dan add sampai volume $100 \mathrm{ml}$ sehingga didapatkan baku induk $100 \mathrm{ppm}$.

\section{Penentuan panjang gelombang maksimum dan Penentuan operating time}

Asam galat dipipet sebanyak $4 \mathrm{ppm}$ dan dimasukan ke dalam labu ukur 10 ml, ditambahkan I $\mathrm{ml}$ reagen folin ciocalteu, kemudian dikocok dan diamkan selama 5 menit. Kedalam larutan tersebut ditambahkan $2 \mathrm{ml}$ larutan $\mathrm{Na}_{2} \mathrm{CO}_{3} \mathrm{I} \%$, dikocok homogen dan didiamkan selama 5 menit. Selanjutnya 
ditambahkan aquadest sampai tepat $10 \mathrm{ml}$ dan dilakukan scanning pada panjang gelombang $\lambda 300-$ $800 \mathrm{~nm}$. Hasil dari pengukuran panjang gelombang maksimum baku asam galat adalah $765 \mathrm{~nm}$. Kemudian dilakukan time scanning sampai IIO menit pada panjang gelombang $765 \mathrm{~nm}$ dan waktu stabil terbaca pada menit ke-90. Penelitian ini mengacu pada penelitian (Amelia, 2015)

\section{Pembuatan kurva baku asam galat dengan reagen folin ciocalteu}

Larutan baku induk asam galat dipipet sejumlah tertentu hingga didapatkan konsentrasi I ppm, 2 ppm, 3 ppm, 4 ppm, 5 ppm, 6 ppm, 7 ppm menggunakan labu ukur $10 \mathrm{ml}$. Tambahkan I ml reagen folin ciocalteu, dikocok dan didiamkan selama 5 menit. Kedalam larutan tersebut ditambah $2 \mathrm{ml}$ larutan $\mathrm{Na}_{2} \mathrm{CO}_{3} \quad$ I5\% dikocok homogen dan didiamkan selama 90 menit. Amati absorbansi yang terukur pada panjang gelombang maksimum. Ulangi pengambilan hingga didapat tujuh konsentrasi kurva baku standar asam galat (Amelia, 2015).

\section{Penetapan kadar tanin ekstrak daun pagoda menggunakan spektrofotometri. \\ Sebanyak $50 \mathrm{mg}$ ekstrak etanol daun} pagoda dilarutkan dengan aquadest sampai volume $50 \mathrm{ml}$. Larutan ekstrak yang diperoleh kemudian dipipet sebanyak $15 \mathrm{ppm}, 20 \mathrm{ppm}, 30 \mathrm{ppm}$, dan ditambah I $\mathrm{ml}$ reagen folin ciocalteu, kemudian dikocok dan didiamkan 5 menit. Ke dalam larutan tersebut ditambahkan $2 \mathrm{ml}$ larutan $\mathrm{Na}_{2} \mathrm{CO}_{3} \mathrm{I}_{5} \%$, dikocok homogen dan didiamkan selama 5 menit dan tambahkan aquadest hingga volume $10 \mathrm{ml}$. Diamkan selama 90 menit, amati absorbansi pada panjang gelombang $765 \mathrm{~nm}$ dengan replikasi sebanyak dua kali. Kadar tanin total dihitung ekivalen dengan asam galat (gallic acid equivalent/ GAE). (Amelia,2015)

\section{Penetapan kadar tanin secara permanganometri}

\section{Pembuatan larutan pereaksi larutan indigocarmin}

Sebanyak 6 gram indigocarmin dilarutkan kedalam $500 \mathrm{ml}$ aquadest dan dipanaskan. Setelah dingin ditambah aquadest sampai satu liter lalu disaring (Sulastri, 2009).

\section{Pembuatan larutan $\mathrm{KMnO}_{4}$}

Ditimbang $\mathrm{KMnO}_{4} \quad 3,2$ gram kemudian dilarutkan I liter aquadest. Didihkan selama IO-I5 menit, kemudian di simpan selama satu malam. Setelah disaring dan diencerkan I liter aquadest larutan $\mathrm{KMnO}_{4}$ standar perlu distandarisasi sebelum dipakai (Sulastri, 2009).

\section{Standarisasi larutan $\mathrm{KMnO}_{4}$ 0,IN}

Ditimbang 0,63 gram kristal asam oksalat, dilarutkan dalam $100 \mathrm{ml}$ aquadest. Ambil $25 \mathrm{ml}$

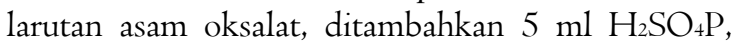
panaskan sampai $70^{\circ} \mathrm{C}$. Selanjutnya dalam keadaan panas dititrasi menggunakan kalium Permanganat $\left(\mathrm{KMnO}_{4}\right)$ standar sampai warna ungu dan tetesan larutan permanganat tidak hilang, catat volume titrasi.

Reaksi : $2 \mathrm{KMnO}_{4}+5 \mathrm{H}_{2} \mathrm{C}_{2} \mathrm{O}_{4}+3 \mathrm{H}_{2} \mathrm{SO}_{4} \rightarrow \mathrm{MnSO}_{4}$

$$
+\mathrm{IOCO}_{2}+\mathrm{K}_{2} \mathrm{SO}_{4}+8 \mathrm{H}_{2} \mathrm{O}
$$

$\mathrm{KMnO} 4=\frac{w(m g) \times 2 \times 25 / 100}{v(m l)}$

Keterangan:

$\mathrm{W}$ : Berat asam oksalat yang ditimbang (mg)

BM : Berat molekul kristal asam oksalat (I26)

$\mathrm{V}$ : Volume titrasi

\section{Penetapan Kadar Tanin dengan metode Permanganometri}

Timbang I,5 gr estrak etanol daun pagoda, masukan kedalam gelas piala $100 \mathrm{ml}$ dan ditambahkan aquadest $50 \mathrm{ml}$. Panaskan pada suhu 40- $60^{\circ} \mathrm{C}$ selama 30 menit. Setelah dingin larutan disaring kedalam labu ukur $250 \mathrm{ml}$, lalu ditambah aquadest hingga tanda batas. Ambil $25 \mathrm{ml}$ larutan tersebut, masukan kedalam erlemeyer dan ditambahkan $20 \mathrm{ml}$ larutan Indigocarmin. Titrasi menggunakan larutan $\mathrm{KMnO}_{4}$ O,I $\mathrm{N}$, titik akhir ditunjukan dengan larutan berwarna menjadi kuning keemasan, pengujian dilakukan sebanyak tiga kali. Penetapan blangko dilakukan dengan cara memipet $20 \mathrm{ml}$ larutan indigocarmin kedalam erlemeyer dan tambahkan aquadest. Titrasi dengan larutan $\mathrm{KMnO}_{4}$ 0,I N, titik akhir ditunjukan dengan larutan berwarna kuning keemasan (Sulastri, 2009).

\section{Analisis Data}

Data yang didapat dalam penelitian penetapan kadar senyawa tanin pada estrak daun pagoda (Clorodenrum paniculantum) adalah data metode spektrofotometri dan permanganometri. Data metode spektrofotometri berupa data absorbansi yang dihitung persamaan $\mathrm{y}=\mathrm{bx}+\mathrm{a}$ dan dilanjutkan dengan perhitungan kadar tanin menggunakan rumus $\%$ Tanin $=\mathrm{cx}_{\mathrm{Vxfp}} /(\mathrm{w}(\mathrm{mg})) \times 100 \%$.

Sedangkan data permanganometri dihitung dengan rumus

$\%$ Tanin $=\frac{(\mathrm{I} 0(\mathrm{~A}-\mathrm{B}) \times \mathrm{N} \times 0,004 \mathrm{I} 6)}{(\text { sampel }(\mathrm{g})} \times 100 \% . .(2)$

kemudian hasil yang didapat akan dideskripsikan dalam bentuk tabel dan grafik. 


\section{Hasil dan Pembahasan}

Uji kualitatif menunjukan bahwa ekstrak daun pagoda positif mengandung senyawa tanin yang dapat dilihat pada Tabel I. Selanjutnya dilanjutkan analisis kuantitatif menggunakan metode spektrofotometri dan permanganometri untuk mengetahui kadarnya.

Tabel I. Hasil pemeriksaan identifikasi senyawa tanin

\begin{tabular}{ccccc}
\hline Sample & Pereaksi & Teori & Hasil & Keterangan \\
\hline Estrak & & Larutan & & \\
etanol & & sample & & Positif \\
daun & $\mathrm{FeCl}_{3}$ & $2 \mathrm{ml}+$ & Hijau & $(+)$ \\
pagoda & & $\mathrm{I}-2$ tetes & kehitaman & Tanin \\
& & pereaksi & & \\
& & $\mathrm{FeCl}_{3}$ & & \\
\hline
\end{tabular}

Pada penetapan kadar tanin secara spektrofotometri menggunakan pereaksi folin ciocalteu, yang didasarkan pada pembentukan kompleks dari molybdenum tungsten blue.. Susanti (20I2) menyatakan bahwa gugus hidroksil pada senyawa fenolik bereaksi dengan reagen folin ciocalteu yang dideteksi dengan spektrotometer pada panjang gelombang maksimum $765 \mathrm{~nm}$. Senyawa fenolik bereaksi dengan folin ciocalteu hanya dalam suasana basa, sehingga ditambahkan Natrium karbonat ( $\mathrm{Na} 2 \mathrm{CO} 3$ ) untuk membuat keadaan basa. Pemilihan asam galat sebagai pembanding pada penelitian ini dikarenakan asam galat memiliki gugus fenol, senyawa yang stabil, murni dan lebih murah dibandingkan pembanding yang lainnya (Underwood dan Day, (200I).

Kurva baku pada penelitian ini menggunakan konsentrasi I ppm, 2 ppm, 3 ppm, 4 ppm, 5 ppm, 6 ppm, 7 ppm menggunakan labu ukur $10 \mathrm{ml}$. Tambahkan I $\mathrm{ml}$ reagen folin ciocalteu, dikocok dan didiamkan selama 5 menit. Kedalam larutan tersebut ditambah $2 \mathrm{ml}$ larutan $\mathrm{Na} 2 \mathrm{CO} 3$ I5\% dikocok homogen dan didiamkan selama 90 menit. Amati absorbansi yang terukur pada panjang gelombang maksimum $765 \mathrm{~nm}$. Ulangi pengambilan hingga didapat tujuh konsentrasi kurva baku standar asam galat (Amelia, 2015)

Amati Absorbansi yang terukur pada konsentrasi kurva baku asam galat yang di buat. Selanjutnya hitung nilai absorbansi dengan rumus regersi linear $y=a x+b$ sehingga di dapat nilai regresi liniernya. Hasil pengukuran yang dilakukan didapatkan nilai $r$ yang baik $(r=0,998 I)$ dengan persamaan garis $y=0,1093 x-0,0094$. Hasil dapat dilihat pada gambar I.

\section{Grafik absorbansi kurva baku}

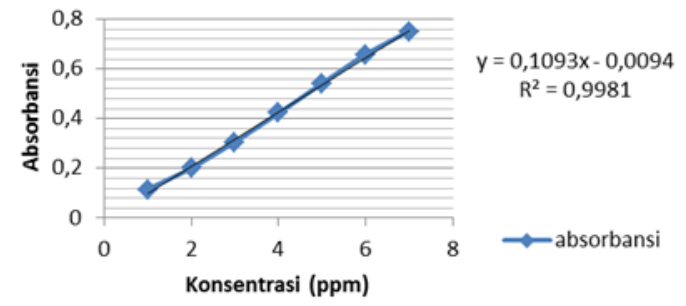

Gambar I. Grafik Absorbansi kurva baku (absorbasi vs konsentrasi)

Penetapan kadar sempel ekstrak daun pagoda menggunakan larutan sampel konsntrasi I5 ppm, 20 ppm dan 30 ppm. Dengan langkah yang sama dan pengulangan sebanyak 3 kali, kadar tanin total dihitung ekivalen dengan asam galat (gallic acid equivalent/ GAE). didapatkan hasil rata-rata I5 ppm yaitu 4,I43\%, 20 ppm yaitu 5,543\% dan 300 ppm yaitu 7,66\%. Hasil Analisa kadar ekstrak tanin dengan metode spektrofotometri UV-Vis dapat dilihat pada tabel I.

Tabel I. Hasil Analisa kadar tanin ekstrak daun pagoda dengan metode spektrofotometri UV-Vis

\begin{tabular}{|c|c|c|c|c|c|}
\hline $\begin{array}{l}\text { Bobot Sample } \\
\text { (mg) }\end{array}$ & $\begin{array}{l}\text { Konsentrasi } \\
\text { (bpj) }\end{array}$ & $\begin{array}{c}\text { Nilai } \\
\text { absorbansi }\end{array}$ & $\begin{array}{l}\text { Hasil nilai regresi } \\
\text { linier }(\mathrm{mg} / \mathrm{ml})\end{array}$ & $\begin{array}{c}\text { kadar tanin } \\
(\%)\end{array}$ & $\begin{array}{c}\text { Rata - rata tanin } \\
(\%)\end{array}$ \\
\hline \multirow{9}{*}{50} & \multirow{3}{*}{ I5 ppm } & 0,419 & $3,7614 \mathrm{mg} / \mathrm{ml}$ & 3,76 & \multirow{3}{*}{$4, \mathrm{I} 43$} \\
\hline & & 0,495 & $4,4587 \mathrm{mg} / \mathrm{ml}$ & 4,45 & \\
\hline & & 0,496 & $4,220 \mathrm{Img} / \mathrm{ml}$ & 4,22 & \\
\hline & \multirow{3}{*}{$20 \mathrm{ppm}$} & 0,609 & $5,587 \mathrm{mg} / \mathrm{ml}$ & 5,58 & \multirow{3}{*}{5.543} \\
\hline & & $0,61 \mathrm{I}$ & $5,522 \mathrm{mg} / \mathrm{ml}$ & 5,52 & \\
\hline & & $0,6 \mathrm{I} 2$ & $5,532 \mathrm{mg} / \mathrm{ml}$ & 5,53 & \\
\hline & \multirow{3}{*}{$30 \mathrm{ppm}$} & 0,796 & $7,220 \mathrm{mg} / \mathrm{ml}$ & 7,22 & \multirow{3}{*}{7,66} \\
\hline & & 0,859 & $7,798 \mathrm{mg} / \mathrm{ml}$ & 7,98 & \\
\hline & & 0,863 & $7,783 \mathrm{mg} / \mathrm{ml}$ & 7.78 & \\
\hline
\end{tabular}

Selanjutnya dilakukan penetapan kadar dengan menggunakan metode permanganometri. Prinsip metode permanganometri ini adalah oksidasi, dimana adanya oksidator kuat yang mampu mengoksidasi sebagian besar reduktor secara kuantitatif, selain itu, terbentuknya larutan yang berwarna sekaligus menjadikannya sebagai indikator titik ekuvalensi (kelebihan I tetes 0,IN sudah dapat mengasilkan warna ungu terang dalam volume yang besar). Larutan permanganat yang dibuat biasanya mempunyai konsentrasi sekitar 0,I N (Mulyono, 2008). 
Sampel yang telah diberiperlakuan dan telah diberi larutan Indigocarmin di titrasi menggunakan larutan $\mathrm{KMnO}_{4}$ 0, I N. titik akhir ditunjukan dengan larutan berwarna menjadi kuning keemasan. Pengujian dilakukan sebanyak tiga kali dan hasil yang didapat dibandingkan dengan volume titrasi blanko. Persen kadar yang didapat menggunakan metode permangano metri adalah $0,443 \%$. Hasil penetapan kadar dengan menggunakan metode permanganometri dapat dilihat pada tabel II.

Tabel II. Hasil penetapan kadar dengan menggunakan metode permanganometri.

\begin{tabular}{cccc}
\hline No & \multicolumn{2}{c}{ Volume } & \multicolumn{2}{c}{ Volume } & Kadar \\
titrasi blanko & $\begin{array}{l}\text { titrasi estrak } \\
\text { tanin (ml) } \\
\text { daun } \\
(\mathrm{ml})\end{array}$ & $\begin{array}{r}\text { pagoda } \\
\text { ( })\end{array}$ & \\
\hline $\mathrm{I}$ & $\mathrm{I} 2,6$ & $\mathrm{I} 4,2$ & \\
2 & $\mathrm{I} 2,8$ & $\mathrm{I} 4, \mathrm{I}$ & \\
3 & $\mathrm{I} 2,6$ & $\mathrm{I} 4,3$ & 0,443 \\
$\begin{array}{c}\text { Rata- } \\
\text { rata }\end{array}$ & $\mathrm{I} 2,6$ & $\mathrm{I} 4,2$ & \\
\hline
\end{tabular}

Telah dilakukan penetapan kadar ekstrak daun pagoda menggunakan metode spektrofoto metri dan metode permanganometri. Hasil yang didapatkan adalah kadar tanin ekstrak daun pagoda menggunakan metode spektrofotometri konsentrasi I5 ppm (4,I43\%), 20 ppm (5,543\%) dan 30 ppm $(7,66 \%)$ terukur jauh lebih besar dibandingkan dengan menggunakan metode permanganometri adalah $0,443 \%$. Hal ini membuktikan metode spektrofotometri lebih baik karena hasil yang diperoleh lebih akurat dan memliliki ketelitian yang tinggi dibanding dengan metode Permanganometri.

\section{Simpulan dan Saran}

Dari penelitian maka dapat disimpulkan bahwa Hasil penetapan kadar tanin ekstrak daun pagoda menggunakan metode spektrofotometri konsentrasi I5 ppm (4,I43\%), $20 \mathrm{ppm}(5,543 \%)$ dan $30 \mathrm{ppm}$ $(7,66 \%)$ terukur jauh lebih besar dibandingkan dengan menggunakan metode permanganometri adalah $0,443 \%$. Hal ini membuktikan metode spektrofotometri lebih baik karena hasil yang diperoleh lebih akurat dan memliliki ketelitian yang tinggi dibanding dengan metode Permanganometri.

\section{Daftar Pustaka}

Depkes RI (1995). Farmakope Indonesia. Edisi empat, Jakarta: Departemen Kesehatan Ri. Hal 32

Amelia, FR (2015). Penentuan jenis tanin dan penetapan kadar tanin dari buah bungur muda (Lagerstroemia speciosa Pers.) secara spektrofotometri dan permanganometri.
Calypta : Jurnal Ilmiah Mahasiswa Universitas Surabaya. Vol.4 No.2.

Fitriana, I., (2018), Efek Pemberian Ekstrak Daun Pagoda (Clerodendrum paniculantum) Terhadap Kadar IL-6 pada Mammae Tikus Betina Sprague Dawley yang di Induksi Staphylococcus Aureus, Sekripsi Sekolah Pasca Sarjana Universitas Hasanudin, Makassar.

Hafiz, I., Rosidah and Silalahi, J, (2016), Antioxidant and anti-inflammatory activity of pagoda leaves (Clerodendrum paniculatum) ethanolic extract in white male rats (Rattus novergicus), International Journal of PharmTech Research, 9(5), pp. 165-170.

Hayati, Elok Kamilah, A Ghanaim Fasyah, Dan Lailis Sa'adah. (2010). Fraksinasi Dan Identifikasi Senyawa Tanin Pada Daun Belimbing Wuluh (Averrhoa Bilimbi L.). Jurnal Kimia 4(2): 193-200.

Mulja M dan Suharman, (1995). Analisa Kimia Kualitatif, edisi IV. Terjemahan oleh Lis Spyan, 200I, Erlangga, Jakarta, 290-29I.

Mulyono, H., (2008), Membuat reagen kimia,cetakan II, Hal I5I,PT Bumi Aksara J1.Sawo Raya No.I8. Jakarta.

Nurrani, Lis, Supratman Tabba, Dan Hendra S Mokodompit. (20I5). Kearifan Lokal Dalam Pemanfaatan Tumbuhan Obat Oleh Masyarakat Di Sekitar Taman Nasional Aketajawe Lolobata, Provinsi Maluku Utara (Local Wisdom In The Utilization Of Medicine Plants By Community Around Aketajawe Lolobata National Park, North Maluku Prov). Jurnal Penelitian Sosial Ekonomi Kehutanan I2(3): 163-75.

Sajaratud D, (2013). Pembuatan Tanin Dari Buah Pinang. Fakultas Ilmu Tarbiya Dan Keguruan Institun Agama Islam Negeri, Sumatera Utara.

Shlivastava,N., Dan Patel, T.(2007). Clerodenrum And Healthcare: An Overview, Medicinal And Aromatic Plant Science And Bioternologi: I (2): 209-223

Sjahid, L.R (2008) Isolasi dan Identifikasi Flavonoid dari daun dewandaru (Eugenia uniflora L.). Skripsi. Universitas muhammadiyah Surakarta.

Sulastri,T. (2009). Analysis of concentration of tannins ethanol and water extract at the pinang sirih seed (Aresa catechu L).I0,59-63

Underwood Al Dan Day Ra, (200I)., Analisa Kimia Kuantitatif, Edisi Iv, Terjemahan Oleh Lis Sopyan, 200I, Erlanga, Jakarta, 290-29I 